\title{
Dynamic Changes of China's Export Specialization
}

\author{
Taegi Kim*, Dan Meng \\ Department of Economics, Chonnam National University, Gwangju, Korea \\ Email: ${ }^{*}$ tgkim@jnu.ac.kr, evelynrainmeng@hotmail.com
}

Received 7 May 2015; accepted 24 May 2015; published 27 May 2015

Copyright (C) 2015 by authors and Scientific Research Publishing Inc.

This work is licensed under the Creative Commons Attribution International License (CC BY).

http://creativecommons.org/licenses/by/4.0/

(c) (;) Open Access

\begin{abstract}
This paper analyzes the dynamic changes of China's export specialization during the period of 1987-2011. China's exports have increased rapidly from 1.60 percent of the world market in 1987 to 10.31 percent in 2011. China's export specialization has changed from labor-intensive goods to capital-intensive goods, and especially, has moved from low technology industries to high technology industries. The regression results show that even with the de-specialization pattern evident in all countries, China's de-specialization tendency is stronger than that of advanced countries. This de-specialization can be attributed to China's intra-industry trade and the quality improvement of China's exporting goods.
\end{abstract}

\section{Keywords}

China, Comparative Advantage, Dynamic Change, Export Specialization, Intra-Industry Trade

\section{Introduction}

China has developed into a dynamic market-oriented economy with institutional reforms and open economy policies. The effect of the switch from a centrally planned economic framework to a market-economy was enormous. Since the liberalization of the foreign trade system at the end of 1978, China has experienced remarkable export growth; exports have increased from 39.4 billion dollars in 1987 to 1898.3 billion dollars in 2011, and the average growth rate was 17.52 percent per year from 1987 to 2011. As a result, China's export share in total world exports has grown from 1.60 percent in 1987 to 10.31 percent in $2011^{1}$. Industry specialization patterns have changed dynamically with its economic growth.

This paper studies the dynamic changes of China's export specialization from 1987 to 2011. We used trade data for China and 16 developed countries. China's dynamic change is compared with the changes of advanced

*Corresponding author.

${ }^{1}$ These export shares are calculated from the World Development Indicators database (World Bank). 
countries, whether it is faster or slower than the advanced countries.

The Heckscher-Ohlin model predicts that a country will export commodities that are relatively intensive in the factor with which the country is relatively well endowed. Thus, a labor-abundant country will export labor-intensive goods, while a capital-abundant country will export capital-intensive goods. As a labor-abundant country, China exports labor-intensive products to world markets, and China's comparative advantage has evolved along with its economic development. In a transition economy such as China, production structure and comparative advantage industry change as the factor endowment changes.

Many studies have analyzed the specialization and convergence of industrial structure. Yue [1] demonstrates that China's export patterns have changed over time, and that there are distinct differences in export patterns between the coastal regions and the interiors in China. Bender and $\mathrm{Li}$ [2] examines whether there is a relation between changes in export patterns among different regions and shifts of comparative advantage between regions, using the data of the East Asian and Latin American regions over the period 1981-1997. Widodo [3] examines shifts in specialization pattern of China's and India's exports, and finds that the comparative advantage industries of both China and India have changed.

Xing [4] analyzes the dynamic changes of China's intra-industry trade with its major trading partners, Japan and the US, from 1980 to 2004. The estimated intra-industry indices demonstrate that the Sino-Japanese intraindustry trade is concentrated in electrical and machinery sectors, and that Sino-US intra-industry trade is relatively high in chemical and food sectors. Intra-industry trade is traditionally considered as a phenomenon seen in trade between similar industrialized countries. Helpman and Krugman [5] demonstrated that high degrees of similarity in factor endowment and a small gap in income levels facilitate the development of intra-industry trade. Grubel and Lloyd [6] showed that a high proportion of intra-industry trade existed between industrialized countries, and Greenaway and Milner [7] also found that intra-industry trade was prevalent between high income countries with similar factor endowments and factor prices.

This study presents several improvements to earlier studies of China's export specialization. The data coverage of this study is broader than that of the previous studies, the time span is slightly longer from 1987 to 2011 , and a much lower level of industry aggregation is considered. Second, this study focuses on the changes of China's export share in the world market as a whole, not merely in a selected reference group. Third, we use regression analysis to examine the dynamic changes of specialization, where we compare China's changes with those of advanced countries. Finally, we explain the reasons for China's export de-specialization.

This paper is organized as follows. Section 2 presents the rapid increase of China's exports to the world. Section 3 discusses the changes of China's comparative advantage with the revealed comparative advantage index. Section 4 analyzes China's dynamic changes with regression analysis. Section 5 examines the reasons for China’s export de-specialization. Finally, the conclusions are presented in Section 6.

\section{Increase in China's Exports}

Figure 1 shows the changes of China's world market share, which has increased from 1.86 percent in 1987 to 13.71 percent in $2011^{2}$. Among the total shares, the share of comparative advantage goods increased from 1.56 percent in 1987 to 11.31 percent in 2011, and the share of comparative disadvantage goods only increased from $0.30 \%$ in 1987 to $2.39 \%$ in 2011. The export of comparative advantage goods leads the increase in China’s total export.

Table 1 lists China’s major exporting goods in 1987 and 2011, with the export share and symmetric revealed comparative advantage index (SRCA) ${ }^{3}$. Table 1 reveals that all the SRCA values of top-ten commodities are positive, which means that they are comparative advantage goods. Comparing the top-ten lists of the two years shows that China's major exporting goods changed significantly over time. China's top-ten exporting goods were dominated by labor intensive goods included in SITC 6 and SITC 8 (such as apparel and textile) in 1987, but changed to capital intensive goods included in SITC 7 (such as telecommunication equipment and electric machinery) in 2011. In addition, the total export share of China's top-ten products was 40.10 percent in 1987 and 36.85 percent in 2011, showing that China’s total exports are dominated by these few products.

The manufacturing industries are classified into high technology, medium-high technology, medium-low technology and low technology groups [8]. The data in Table 2 show each group's export share in China's total

\footnotetext{
${ }^{2}$ These export shares are calculated from the UN Comtrade database.

${ }^{3}$ The methodology to calculate SRCA index is explained in Section III.
} 


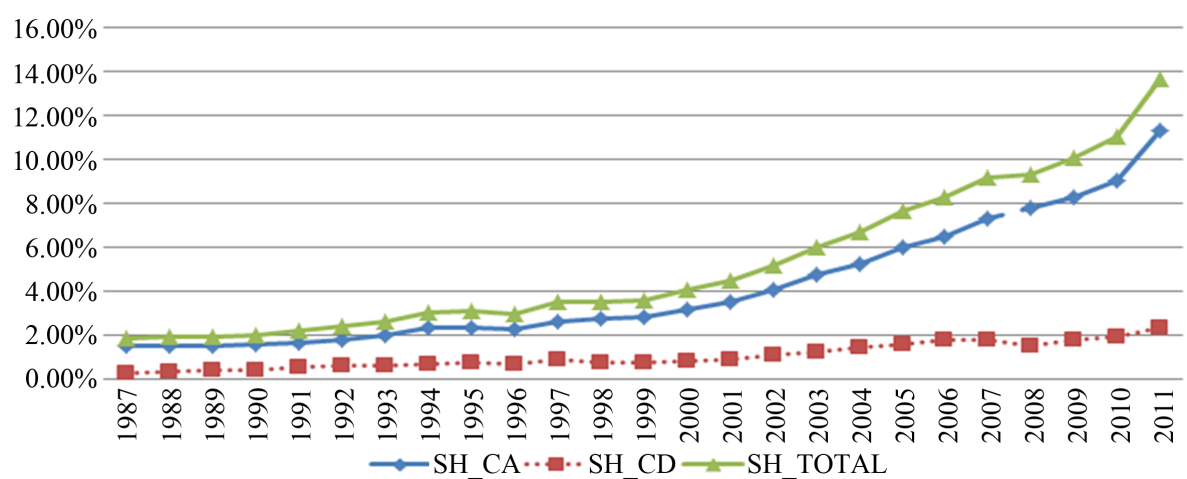

Figure 1. Changes of China's world market share. Note: SH_CA isworld market share of China's comparative advantage goods, SH_CD is that of China's comparative disadvantage goods, and SH_TOTAL is that of China's total exports.

Table 1. China’s top-10 exporting goods in 1987 and 2011.

\begin{tabular}{|c|c|c|c|c|c|}
\hline & Rank & SITC & Industry Description & Share (\%) & SRCA \\
\hline & 1 & 333 & Crude petroleum and oils obtained from bituminous minerals & 7.96 & 0.408 \\
\hline & 2 & 931 & Special transactions, commodity not classified according to class & 6.69 & 0.553 \\
\hline & 3 & 845 & outerwear knitted or crocheted, not elastic nor rubberized & 4.95 & 0.696 \\
\hline & 4 & 652 & Cotton fabrics, woven (not including narrow or special fabrics) & 4.29 & 0.762 \\
\hline & 5 & 784 & Motor vehicle parts and accessories, nes & 3.64 & 0.088 \\
\hline \multirow[t]{11}{*}{1987} & 6 & 651 & Textile yarn & 3.32 & 0.550 \\
\hline & 7 & 843 & Women, girls, infants outerwear, textile, not knitted or crocheted & 2.40 & 0.497 \\
\hline & 8 & 894 & Baby carriages, toys, games and sporting goods & 2.37 & 0.588 \\
\hline & 9 & 658 & Made-up articles, wholly or chiefly of textile materials, nes & 2.29 & 0.788 \\
\hline & 10 & 653 & Fabrics, woven, of man-made fibres (not narrow or special fabrics) & 2.18 & 0.519 \\
\hline & Total & & & 40.10 & \\
\hline & 1 & 764 & Telecommunication equipment, nes; parts and accessories, nes & 8.54 & 0.456 \\
\hline & 2 & 752 & Automatic data processing machines and units thereof & 8.43 & 0.575 \\
\hline & 3 & 776 & Thermionic, microcircuits, transistors, values, etc & 3.66 & 0.038 \\
\hline & 4 & 845 & outerwear knitted or crocheted, not elastic nor rubberized & 3.04 & 0.613 \\
\hline & 5 & 778 & Electrical machinery and apparatus, nes & 2.46 & 0.266 \\
\hline \multirow[t]{6}{*}{2011} & 6 & 821 & Furniture and parts thereof & 2.38 & 0.437 \\
\hline & 7 & 793 & Ships, boats and floating structures & 2.30 & 0.328 \\
\hline & 8 & 851 & Footwear & 2.07 & 0.540 \\
\hline & 9 & 759 & Parts, nes of and accessories for machines of headings 751 or 752 & 2.03 & 0.251 \\
\hline & 10 & 894 & Baby carriages, toys, games and sporting goods & 1.92 & 0.510 \\
\hline & Total & & & 36.85 & \\
\hline
\end{tabular}


Table 2. Export share of manufactured industries based on technology (\%).

\begin{tabular}{ccccc}
\hline & Low & Medium-low & Medium-high & High \\
\hline $\mathbf{1 9 8 7 - 1 9 9 0}$ & 46.43 & 8.57 & 14.45 & 6.69 \\
$\mathbf{1 9 9 1 - 1 9 9 5}$ & 44.11 & 10.07 & 15.16 & 10.48 \\
$\mathbf{1 9 9 6 - 2 0 0 0}$ & 35.63 & 12.09 & 19.04 & 16.26 \\
$\mathbf{2 0 0 1 - 2 0 0 5}$ & 27.52 & 11.48 & 21.67 & 26.53 \\
$\mathbf{2 0 0 6 - 2 0 1 1}$ & 21.82 & 14.25 & 26.71 & 28.53 \\
\hline
\end{tabular}

exports. In order to reduce the variance of a certain year, we used period average values. The export shares of higher technology industry exhibit increasing trends, whereas that of low technology industry shows a downward trend. For instance, the export share of both medium-high and high technology industries increased from 21.14 percent in 1987-1990 to 55.24 percent in 2006-2011. However, the export share of low technology industry decreased from 46.43 percent in 1987-1990 to 21.82 percent in 2006-2011. This implies that the higher technology industry has become more important as China's major exporting industry.

\section{Changes of Comparative Advantage}

\subsection{Data}

This paper uses data on trade statistics published by the United Nations (UN), namely the United Nations Commodity Trade Statistics Database (UN COMTRADE) from 1987 to 2011. We selected 16 advanced countries as the reference countries to compare the changes of China's trade pattern. Throughout this study, we refer to a product as a three-digit level of SITC (Standard International Trade Classification).

\subsection{Measure of Comparative Advantage}

The export specialization of the industry is measured by an index of revealed comparative advantage (RCA). The RCA measures the intensity of a country's exports of an industry relative to the intensity of world exports of that industry [9]. The formula is expressed as follows:

$$
\mathrm{RCA}_{i k}=\frac{X_{i k} / \sum_{i=1} X_{i k}}{X_{i w} / \sum_{i=1} X_{i w}}
$$

$x_{i k}=$ a country $k$ 's export of industry $i, \quad \sum_{i=1} X_{i k}=$ total exports of the country $k$;

$x_{i w}=$ world exports of industry $i, \sum_{i=1} X_{i w}=$ total world exports.

The RCA index ranges between zero and infinity $(0 \leq$ RCA $\leq \infty)$. RCA values greater than 1 indicate that a country has a comparative advantage, whereas those less than 1 reveal a comparative disadvantage. In case of RCA index, the range of comparative advantage $(1<$ RCA $\leq \infty)$ is much larger than that of comparative disadvantage $(0 \leq \mathrm{RCA}<1)$. A skewed distribution between comparative advantage and comparative disadvantage violates the assumption of normality of the error term in regression analysis. The logarithmic transformation of RCA alleviates the skewness problem [10], but a problem remains since small RCA values are transformed to high negative $\ln (R C A)$ values.

In order to solve the asymmetric problem of RCA index, we used an SRCA index. The SRCA index is formulated as follows [11] [12].

$$
S R C A_{i k}=\frac{\left(R C A_{i k}-1\right)}{\left(R C A_{i k}+1\right)}
$$

The SRCA index ranges from -1 to 1 . SRCA values greater than zero imply that the country has a comparative advantage in industry $i$, whereas SRCA values less than zero mean that the country has a comparative disadvantage in industry $i$.

\subsection{Changes of Comparative Advantage}

Table 3 shows the changes of average SRCA for SITC one-digit level. From Table 3, the following results can 
Table 3. Changes of SRCA in China: 1987-2011.

\begin{tabular}{ccccccccccc}
\hline & SITC 0 & SITC 1 & SITC 2 & SITC 3 & SITC 4 & SITC 5 & SITC 6 & SITC 7 & SITC 8 \\
\hline $\mathbf{1 9 8 7}$ & 0.20 & -0.43 & 0.28 & 0.23 & -0.37 & -0.24 & 0.14 & -0.60 & 0.31 \\
$\mathbf{1 9 9 1}$ & 0.15 & -0.27 & 0.07 & -0.11 & -0.33 & -0.25 & 0.12 & -0.33 & 0.42 \\
$\mathbf{1 9 9 6}$ & -0.03 & -0.14 & -0.17 & -0.32 & -0.31 & -0.23 & 0.11 & -0.26 & 0.49 \\
$\mathbf{2 0 0 1}$ & -0.09 & -0.49 & -0.32 & -0.50 & -0.76 & -0.32 & 0.10 & -0.06 & 0.44 \\
$\mathbf{2 0 0 6}$ & -0.30 & -0.72 & -0.62 & -0.76 & -0.81 & -0.39 & 0.13 & 0.12 & 0.38 \\
$\mathbf{2 0 1 1}$ & -0.38 & -0.74 & -0.72 & -0.77 & -0.91 & -0.30 & 0.11 & 0.16 & 0.37 \\
\hline
\end{tabular}

Note: We calculated the SRCA index for SITC 3-digit level, and then calculated average values of SRCA for SITC 1-digit level.

be obtained: SITC 1, 4 and 5 are long-term comparative disadvantage goods; SITC 0, 2 and 3 changed from comparative advantage goods in the initial years to comparative disadvantage goods since the 1990s; SITC 6 and 8 are long-term comparative advantage goods; and SITC 7 changed from comparative disadvantage goods in the initial years to comparative advantage goods since 2003.

To examine the structural changes in the patterns of China's comparative advantage, we used the Spearman's rank correlations on SRCA across periods. The values of Spearman's rank correlation coefficients ranged from minus one to one. The correlation coefficient closer to minus one implies that the shift in comparative advantage is "more dynamic", whereas the correlation coefficient closer to one implies that the shift in comparative advantage is "less dynamic".

Table 4 shows Spearman's rank correlation coefficients in 1987, 1995, 2003 and 2011. The China's comparative advantages are dynamic rather than static. For example, the coefficients for 1987 with 1995, 2003 and 2011 are $0.659,0.486$, and 0.264 , respectively, which decreases from short term to long term. The results are similar to 1995 or 2003, in that the correlation coefficient between any two years is inversely correlated with the period between the two years. This implies that China's pattern of comparative advantage has changed continuously over time.

\section{Change of Export Pattern: Specialization or De-Specialization}

\subsection{Regression Analysis}

We can show the structural changes of China's export patterns by comparing the SRCA values of the two years. For the export specialization pattern, there are four possible situations: 1) unchanged pattern; 2) specialization pattern; 3) de-specialization pattern; and 4) reversed pattern. In order to test whether China tended to become more or less specialized across sectors, we use the method proposed by Cantwell [13], which was developed from a "Galtonian" regression model presented by Hart and Prais [14]. The specialization trend is tested by the following regression equation.

$$
S R C A_{i k}^{t_{2}}=\propto_{0}+\beta_{1} S R C A_{i k}^{t_{1}}+\beta_{2}\left(S R C A_{i k}^{t_{1}} \times D C\right)+\varepsilon_{i k}
$$

The superscripts $t_{1}$ and $t_{\text {, }}$ refer to the initial year and the final year, respectively. The dependent variable, SRCA at time $t_{2}$, is tested against the independent variable, which is the SRCA of the initial year $t_{1}$. DC is China dummy variable which is 1 for China and 0 for elsewhere. $\alpha$ and $\beta$ are regression parameters and $\gamma$ is a residual term. $\beta_{1}$ is the regression coefficient for all countries, and $\beta_{2}$ is the regression coefficient for China.

In Equation (3), $\beta_{1}=1$ corresponds to an unchanged pattern from $t_{1}$ to $t_{\text {, }}$, which means that the SRCA of the final year is the same as that of the initial year. If $\beta_{1}>1$, the absolute value of the initial SRCA becomes larger at the final year. That is, the SRCAs of the final year move away from zero, which implies that the pattern of specialization is strengthened. Thus $\beta_{1}>1$ can be termed $\beta$-specialization. Similarly, when $0<\beta_{1}<1$, the absolute value of the initial SRCA becomes smaller at the final year. That is, the SRCAs of the final year approach to zero. Thus $0<\beta_{1}<1$ can be termed $\beta$-de-specialization. In the special case where $\beta_{1}<0$, the comparative advantage of industries has been reversed. That is, the industry which is in comparative advantage at the initial year changed to comparative disadvantage in the final year.

The coefficient $\beta_{2}$ shows the difference between China and the other countries. A positive value of $\beta_{2}$ indi- 
Table 4. Industrial SRCA correlation analysis.

\begin{tabular}{ccccc}
\hline Year & $\mathbf{1 9 8 7}$ & $\mathbf{1 9 9 5}$ & $\mathbf{2 0 0 3}$ & $\mathbf{2 0 1 1}$ \\
\hline $\mathbf{1 9 8 7}$ & 1.000 & 0.659 & 0.486 & 0.264 \\
$\mathbf{1 9 9 5}$ & & 1.000 & 0.831 & 0.638 \\
$\mathbf{2 0 0 3}$ & & & 1.000 & 0.805 \\
$\mathbf{2 0 1 1}$ & & & & 1.000 \\
\hline
\end{tabular}

Note: The numbers are Spearman's rank correlation coefficients between each pair of years.

cates that China's coefficient is larger than that of the other countries, whereas a negative $\beta_{2}$ value implies that China's specialization is slower than that of the other countries.

The data include China and the following 16 advanced countries: Australia, Austria, Canada, Denmark, Finland, France, Germany, Italy, Japan, Netherlands, New Zealand, Norway, Sweden, Switzerland, United Kingdom, and USA. As a time interval, we selected 1 year, 8 years, and 24 years. The regression was done by selecting the SRCAs of the two years, and we used panel regression analysis that considers the fixed effect for the period.

Table 5 shows the regression results for short-term (1-year interval), mid-term (8-year interval), and longterm (24-year interval). The $\beta_{1}$ value smaller than 1 reveals changes in the export pattern: $\beta_{1}$ is 0.976 in shortterm, 0.887 in mid-term, and 0.742 in long-term. The estimated values of $\beta_{1}$ range from 0 to 1 , which represents de-specialization. The magnitude of $\beta_{1}$ becomes smaller decreases as the time interval of the two years becomes longer, which implies that trade specialization changes much more in the long run.

All the $\beta_{2}$ coefficients in Table 5 are negative and statistically significant. Note that $\left(\beta_{1}+\beta_{2}\right)$ denotes the changes of trade specialization for China, while $\beta_{1}$ denotes the changes of trade specialization for the advanced countries. Thus, the negative value of $\beta_{2}$ tells indicates that China's trade patterns change faster than the advanced countries. The absolute value of $\beta_{2}$ in the long-term is much larger than that in the short-term, which further implies that China's trade pattern has changed more rapidly than those of the advanced countries.

\subsection{Standard Deviation Analysis}

There is another test for checking the degree of specialization changes. If the dispersion of a country's SRCA distribution increases, it means that the degree of specialization increases. We term this $\sigma$-specialization. A decreasing dispersion means that the degree of specialization decreases. We term this $\sigma$-de-specialization. Thus, the standard deviation $(\sigma)$ of SRCAs measures whether the level of specialization has increased or decreased between the two periods. The specialization increases if $\sigma$ increases, but decreases if $\sigma$ decreases ${ }^{4}$.

We calculated the standard deviation $(\sigma)$ of SRCAs for each year. Figure 2 shows the changes of $\sigma$ for China and the advanced countries. The value of $\sigma$ decreases both in China and in advanced countries, which indicates that a de-specialization pattern prevails in all countries. However, China's $\sigma$ decreases more rapidly than that of the advanced countries, which indicates that the de-specialization tendency is stronger in China than in the advanced countries. These $\sigma$ analysis results are similar to the regression analysis results, in that China's specialization has changed faster than that of the advanced countries.

In addition, the magnitudes of China's $\sigma$ are larger than those of the advanced countries in all years, and China's $\sigma$ converges to that of the advanced countries. This implies that China's export pattern has become similar to that of the advanced countries over time, even if China's exports are more specialized than those of advanced countries.

\section{Why China Has Moved to De-Specialization}

De-specialization usually arises when intra-industry trade is becoming increasingly important in the economy, and is often observed for trading partners at an advanced stage of development [12]. Since intra-industry trade is the simultaneous imports and exports of goods in the same industry, an increase in intra-industry trade means that specialization in a certain industry has decreased.

\footnotetext{
${ }^{4}$ See more from Dalum, Laursen and Villumsen [15] and Laursen [11].
} 


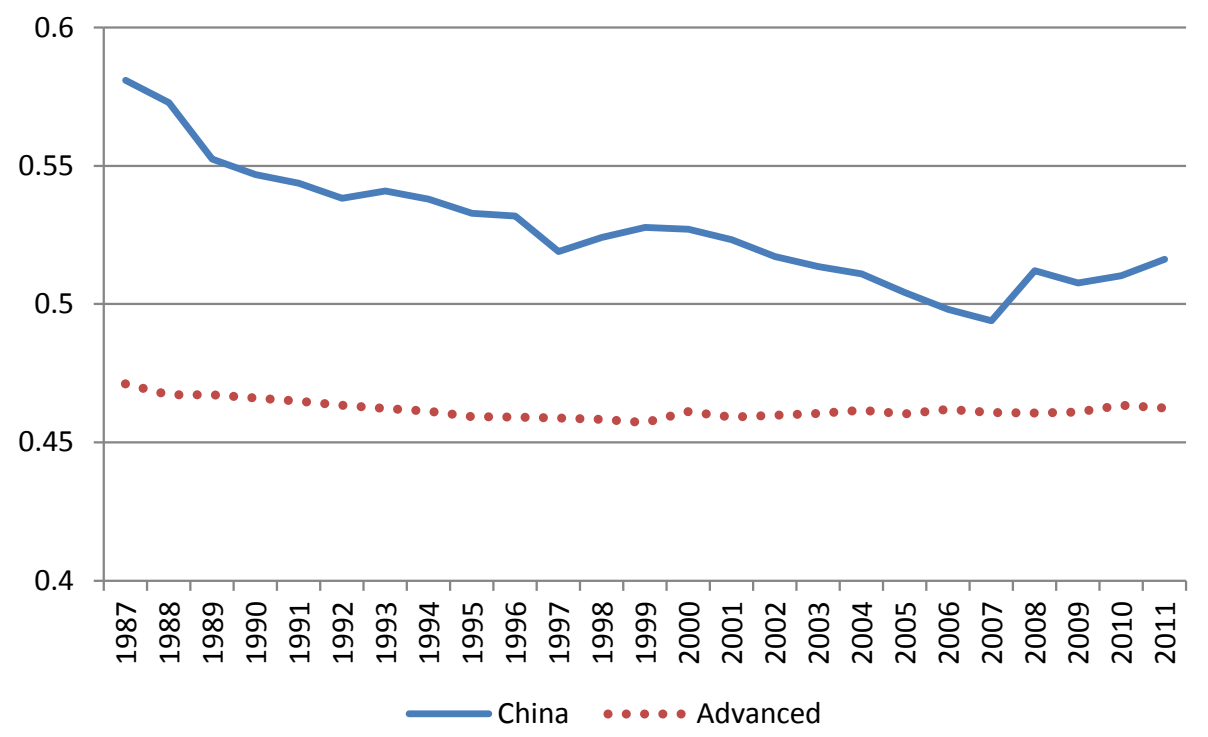

Figure 2. Standard deviation of SRCA for each group.

Table 5. Changes of export specialization from 1987 to 2011.

\begin{tabular}{cccc}
\hline & (1) Short-term (1year) & (2) Mid-term (8 year) & (3) Long-term (24 year) \\
\hline Intercept & $-0.0003(0.48)$ & $0.003(0.70)$ & $0.007(0.78)$ \\
$\boldsymbol{\beta}_{\mathbf{1}}$ & $0.976^{* * *}(1346.86)$ & $0.887^{* * *}(199.34)$ & $0.742^{* * *}(67.29)$ \\
$\boldsymbol{\beta}_{2}$ & $-0.012^{* * *}(4.55)$ & $-0.166^{* * *}(10.43)$ & $-0.533^{* * *}(14.11)$ \\
$\mathbf{R}^{2}$ & 0.956 & 0.795 & 0.584 \\
$\mathbf{N}$ & 95,441 & 11,885 & 3936 \\
\hline
\end{tabular}

Notes: (1) ${ }^{* * *}$ indicate significance level of $1 \%$. (2) t-Statistics are in parentheses.

In empirical studies, the level of intra-industry trade (IIT) in an industry is usually quantified by the GrubelLloyd index, which is defined as:

$$
I I T=\left(1-\frac{\left|X_{i}-M_{i}\right|}{\left(X_{i}+M_{i}\right)}\right) \times 100
$$

where $I I T, X_{i}$ and $M_{i}$ stands stand for the intra-industry trade index, exports and imports in industry $i$, respectively. The index ranges from 0 to 100 , where 0 indicates complete inter-industry trade and 100 implies complete intra-industry trade.

Intra-industry trade tends to be prevalent between countries that are similar in their capital-labor ratios and skill levels, i.e., between countries at a similar level of economic development. And intra-industry trade is also more prevalent in trade of manufactured goods than in that of raw materials or agricultural goods. Therefore, intra-industry trade is most likely to happen in trade of manufactured goods among advanced countries.

China's production technology has increased sharply over the last few years. Additionally, the increasing income level has expanded its preference on product diversity. This implies that China's intra-industry has increased gradually.

Figure 3 shows the increase in China's intra-industry trade. China's IIT levels of all industries exhibit an upward trend, increasing from 36.6 percent in 1987 to 40.6 percent in 2011. Especially, the IIT of manufacturing goods has increased from 40.1 percent in 1987 to 47.2 percent in 2011, while that of primary goods has decreased from 30.2 to 29.8 percent. These results illustrate that the manufactured products play an important role in the increase of China's IIT levels. In 2011, China's IIT in manufactured products was 47.2 percent, which was significantly higher than that in primary products (29.8 percent). 
The increase in intra-industry trade indicates that China's export patterns converge to those of the advanced countries, i.e., China's export specialization moves to de-specialization. The increase in China's IIT is due to the quality improvement of China's exporting goods.

We measured the quality change of China's exporting goods with the export similarity index, which measures the similarity of exporting goods between China and the advanced countries. Export similarity index (ESI) is defined as follows [16].

$$
E S I_{j k}=\sum_{i=1}^{n} \min \left(s_{i j}, s_{i k}\right)
$$

where $i$ is industry, and $j$ and $k$ denote countries. The value of ESI lies between 0 and 1 , with a higher value indicating a higher similarity of export goods of the two countries.

Figure 4 shows the changes of average ESI value between China and the advanced countries from 1987 to 2011. ESI has increased over time, which implies that China's exporting goods have become similar to those of advanced countries. The increasingly similar trade patterns between China and advanced countries reveal the
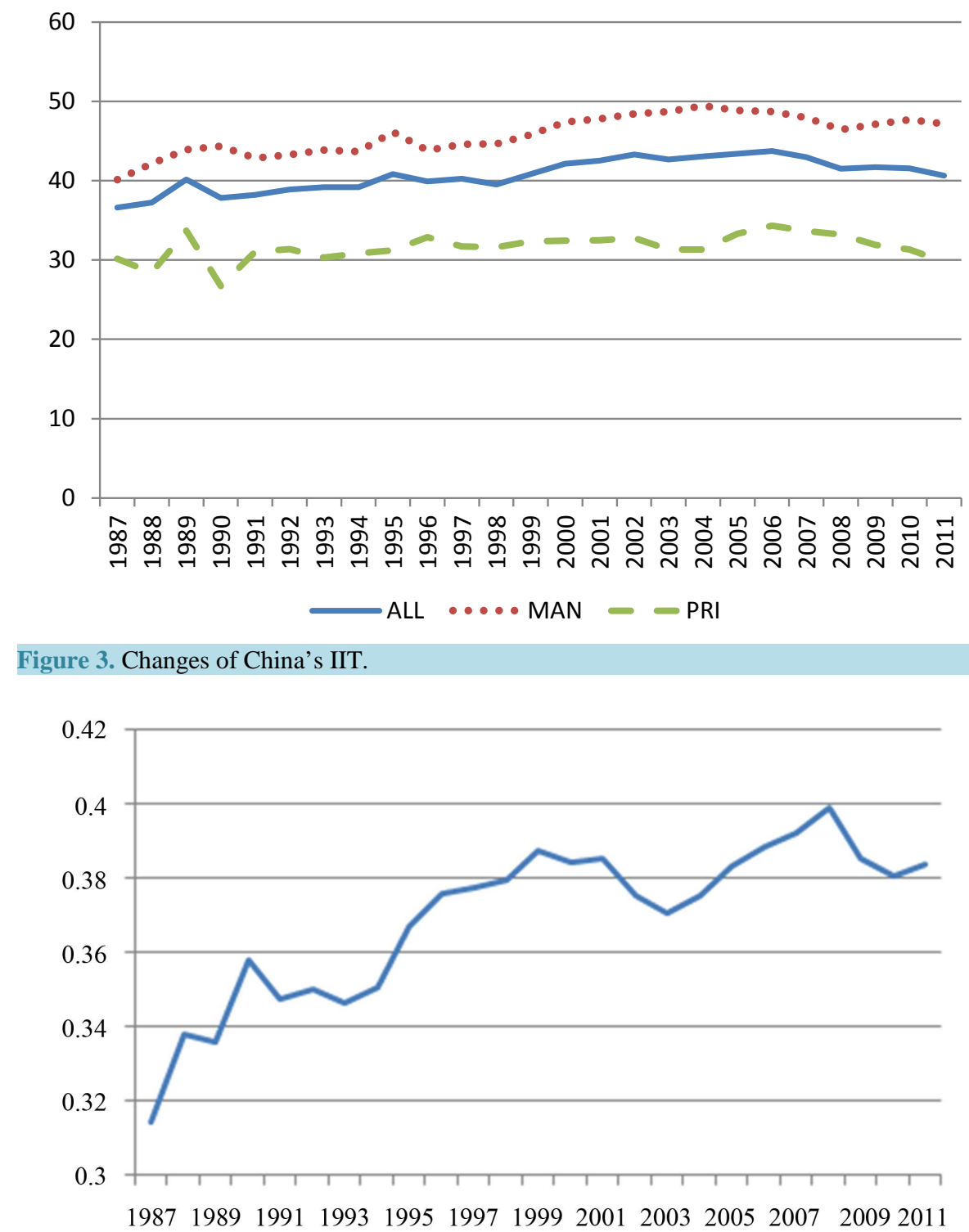

Figure 4. China's export similarity index with the advanced countries. Note: The value of ESI in the figure is the average ESIs, which are calculated between China and each advanced country. 
improved quality of China's exporting goods [17]. As China's exporting goods converge to those of the advanced countries, China's trade pattern moves to de-specialization.

\section{Concluding Remarks}

This paper has analyzed the dynamic changes of China's export specialization by using trade data during the period of 1987-2011. The following conclusions have been established.

First, China's trade structure underwent a dramatic transformation in the analyzed period. China's world market share increased from $1.60 \%$ in 1987 to $10.31 \%$ in 2011. Second, there were significant shifts in comparative advantage patterns from 1987 to 2011: China's export specialization industries moved from low technology to high technology industries. Third, the regression results show that structural changes in China's comparative advantage pattern were dynamic in 1987-2011: China's export pattern reveals a de-specialization trend and this trend is faster than that of the advanced countries. Finally, intra-industry trade has increased and the quality of China's exporting goods has improved over time. These two things led China's trade pattern to de-specialization.

\section{Acknowledgements}

This work was supported by the National Research Foundation of Korea Grant funded by the Korean Government (NRF-2014S1A2A2027622).

\section{References}

[1] Yue, C.J. (2001) Comparative Advantage, Exchange Rate and Exports in China. Paper Prepared for the International Conference on Chinese Economy, CERDI, France.

[2] Bender, S. and Li, K.-W. (2002) The Changing Trade and Revealed Comparative Advantages of Asian and Latin American Manufacture Exports. Economic Growth Center Discussion Paper, No. 843.

[3] Widodo, T. (2008) Shifts in Pattern of Specialization: Case Studies of India and China. Gadjah Mada International Journal of Business, 10, 47-75.

[4] Xing, Y.Q. (2007) Foreign Direct Investment and China's Bilateral Intra-Industry Trade with Japan and the US. Journal of Asian Economics, 18, 685-700. http://dx.doi.org/10.1016/j.asieco.2007.03.011

[5] Helpman, E. and Krugman, P. (1985) Market Structure and Foreign Trade: Increasing Returns, Imperfect Competition and the International Economy. MIT Press, Cambridge, MA.

[6] Grubel, H.G. and Lloyd, P.J. (1975) Intra-Industry Trade: The Theory and Measurement of International Trade in Differentiated Products. Macmillan Press, London.

[7] David, G. andMilner, C. (1986) The Economics of Intra-Industry Trade. Basil Blackwell, Cambridge, MA.

[8] OECD (2003) OECD Science, Technology and Industry Scoreboard, 2003: Annex 1.

[9] Balassa, B. (1965) Trade Liberalisation and Revealed Comparative Advantage. The Manchester School of Economics and Social Studies, 33, 92-124. http://dx.doi.org/10.1111/j.1467-9957.1965.tb00050.x

[10] Soete, L. and Verspagen, B. (1994) Competing for Growth: The Dynamics of Technology Gaps. In: Pasinetti, L.L. and Solow, R.M., Eds., Economic Growth and the Structure of Long-Term Development, MacMillan, London, 272-299.

[11] Laursen, K. (1998) Revealed Comparative Advantage and the Alternatives as Measures of International Specialisation. DRUID Working Paper No. 98-130.

[12] Laursen, K. (2000) Trade Specialisation, Technology and Economic Growth: Theory and Evidence from Advanced Countries. Edward Elgar, Cheltenham.

[13] Cantwell, J. (1989) Technological Innovation and Multinational Corporations. Basil Blackwell, Cambridge, MA.

[14] Hart, P.E. and Prais, S.J. (1956) The Analysis of Business Concentration: A Statistical Approach. Journal of the Royal Statistical Society, 119, 150-191. http://dx.doi.org/10.2307/2342882

[15] Dalum, B., Laursen, K. and Villumsen, G. (1998) Structural Change in OECD Export Specialisation Patterns: De-Specialisation and "Stickiness". International Review of Applied Economics, 12, 423-443. http://dx.doi.org/10.1080/02692179800000017

[16] Finger, J.M. and Kreinin, M.E. (1979) Measure of Export Similarity and Its Possible Uses. Economic Journal, 89, 905-912. http://dx.doi.org/10.2307/2231506

[17] Schott, P. (2006) The Relative Sophistication of Chinese Exports. NBER Working Paper No. 12173, NBER, Cambridge, MA. http://dx.doi.org/10.3386/w12173 